\title{
Evaluation and future framework of green mine construction in China based on the DPSIR model
}

\author{
Jinhui Chen ${ }^{1,2,3}$, Izhar Mithal Jiskani ${ }^{4^{*}}$ (D) Chen Jinliang ${ }^{5}$ and Hui Yan ${ }^{4}$
}

\begin{abstract}
The idea of green mining was proposed as a practical approach to make the mining industry more sustainable than before. Green mining is a contemporary mining model centered on the sustainability of resources, environment, and socio-economic benefits. Its purpose is to develop and apply technologies and processes that increase environmental performance while maintaining competitiveness throughout the entire mining cycle from exploration to post-closure. Although the green mining strategy has achieved considerable significance, there is still a considerable gap between its research and practice. This study evaluates the situation of green mine construction in China and suggests a future framework. First, based on the Driver-Pressure-State-Impact-Response model, an evaluation index system composed of 20 indicators was established. The principal component analysis was used to analyze the data collected from mines situated in Yongcheng, China. The results show that the construction of green mines has improved significantly over the years. Energy consumption and pollutant emissions were minimized, the protection of the ecological environment was realized, and secondary processing of mining waste was practiced. However, there are still some unresolved problems, such as the utilization of solid waste, the recovery ratio from ore processing, and the reuse ratio of coal washing water. Thus, the strategic framework has been proposed for improving green mine construction and the sustainability of the mining industry.
\end{abstract}

Keywords: Green mining, Ecological mining, Green mine construction, Sustainable mining, Mine evaluation, Sustainability

\section{Introduction}

The mining industry plays a significant role in accelerating industrialization and urbanization, as it provides raw materials to meet the growing resource demand. It also contributes to increasing foreign capital investment, exports, and employment, which are critical factors for socio-economic development $[1,2]$. In China, the demand for mineral resources has increased in the past few decades [3, 4]. It is expected that China will continue to be the largest coal market in the world by 2035 [5]. However, the mining industry is facing severe

\footnotetext{
*Correspondence: imjiskani@hotmail.com

${ }^{4}$ School of Mines, China University of Mining and Technology, Xuzhou 221116, China

Full list of author information is available at the end of the article
}

challenges related to environmental pollution and ecological damage that restrict its sustainable development $[6,7]$. Due to constraints in national environmental policy, coal production declined for the first time in 2014 after 14 consecutive years of growth [8,9]. Therefore, attention needs to be paid in adopting more sustainable methods due to the poor environmental image of the industry [10].

Sustainability has become a key issue in the modern world due to its importance in economic growth, social development, and poverty alleviation [2]. Since industrialization has posed an influence on the quality of human life and damage to the natural environment, Awan et al. [11] highlighted that issues of environmental sustainability are widely recognized. Sustainability

(c) The Author(s). 2020 Open Access This article is licensed under a Creative Commons Attribution 4.0 International License, which permits use, sharing, adaptation, distribution and reproduction in any medium or format, as long as you give appropriate credit to the original author(s) and the source, provide a link to the Creative Commons licence, and indicate if changes were made. The images or other third party material in this article are included in the article's Creative Commons licence, unless indicated otherwise in a credit line to the material. If material is not included in the article's Creative Commons licence and your intended use is not permitted by statutory regulation or exceeds the permitted use, you will need to obtain permission directly from the copyright holder. To view a copy of this licence, visit http://creativecommons.org/licenses/by/4.0/. 
performance at the enterprise level relies on social supply chain practices, safety practices, and green manufacturing practices. It provides valuable insights to experts on how enterprises can use such practices to supervise and strengthen the implementation of social manageability [12]. The global mining community has begun to assign a new strategic significance to the term sustainability. Sustainability in mining is not only limited to the economic realm. It incorporates a broad spectrum of organizational characteristics related to social and environmental responsibility [13].

In view of the increasingly adverse impacts of mining on the environment and communities, how to achieve sustainable mining has become a major issue. Since traditional mining has the characteristics of high resource consumption, high pollution, and low efficiency, many researchers are concerned about how to provide scientific solutions. It has been believed that in order to achieve sustainable mining, other measures must be taken to compensate for traditional mining [14]. Therefore, in recent years, mining enterprises have devoted greater attention to the implementation of green innovation [15]. In this regard, Qian et al. [16] put forward the concept of green mining, clarified its technical system, and defined the directions for environment-friendly technology in mining. The purpose of green mining is to reform traditional mining practices to achieve sustainable development of resources, environment, economy, and social benefits [17]. To be more specific, green mining is an advanced mining mode that increases the efficiency of mining activities, decreases the environmental footprint, and allows valuable minerals to be extracted with minimal mining waste at all stages of operations. In addition, it manages mine operations in a way that is safe and harmless for miners, local communities, and the environment. Once a mine has been closed, green mining helps regenerate the mining area to make it safe, and preferably allow other types of land use [18]. The term "ecological mining" also applies to green mining. The construction of new green mines or the transformation of established mines into green mines is regarded as the priority development direction. A number of green mining projects have been initiated to obtain the maximum economic and environmental benefits. According to the "National Program of Mineral Resources: Developing the Green Mining and Constructing the Green Mine", China to have 661 green mines constructed in four phases [19].

Although green mining has received widespread recognition, how to ensure that the mine conforms to principles of green mining remains a problem [20]. One possible way to solve this problem is to develop an evaluation index that can assess the actual situation of the mine. The evaluation index system facilitates the scientific assessment of any specific action, plan, or strategy. In mining, the index system evaluates the strengths and weaknesses of the mining system, which can provide the basis for decision-makers to improve or redesign the current strategic plan of action. The literature emphasizes the value of evaluation models for green mining due to difficulties in assessing mines by direct observations. Therefore, the evaluation index system is considered valuable for ensuring that existing or converted mines are as green as possible [21, 22].

An evaluation index was developed by $\mathrm{Ma}$ and Wang [23] for the Shengli opencast mine that includes air pollution, heavy metal concentration, soil fertility, landscape ecology, and the parameters related to stripping and dumping. Song et al. [24] studied several green mining techniques and established an evaluation index based on the concept of green degree (greenness). Li et al. [25] also proposed an index according to basic conditions and the situation of green mine construction. However, there are some limitations associated with those index systems. Some studies either focus on the concept of green mining or only propose simple indicators, without quantification and evaluation methods. On the other hand, due to the limited applicability and unavailability of comprehensive criteria and indicators, some index systems may lead to unsound decisions. From this perspective, it is clear that the awareness of green mining is being promoted worldwide, but its practice is still in the exploratory stage [26-29]. It implies that a huge research gap exists for an in-depth study on the evaluation and the future framework of green mining development.

Therefore, this study attempts to construct an evaluation index system in accordance with the core principles of green mining. The evaluation index system is based on Driver-Pressure-State-Impact-Response (DPSIR) model. The choice of evaluation criteria and indicators is based on extant literature and expert consultation approach. As a case study, the Yongcheng mining area was evaluated using the principal component analysis (PCA). Finally, countermeasures to promote the construction of green mines in the future are put forward. This study is a step forward in green mining research, aiming to demonstrate the basis for environmentally sustainable mining.

The rest of the article proceeds as follows, where the Methodology section describes the research methods, including the framework of the DPSIR model, the development of the evaluation index, and data analysis. The main results are presented in the Results section. The discussion on achieved results and the future framework are provided in the Discussion section. Finally, a brief conclusion is provided in the last section. 


\section{Methodology}

\section{The DPSIR model framework}

The DPSIR model is a common hierarchical theoretical framework applied to scientific planning and evaluation of an environment, a system, or an industry. The DPSIR model is mostly used in the research of the index system because its practical application over the years has demonstrated its advantages of comprehensiveness, operability, and integrity [30]. Therefore, the DPSIR model was adopted in the present study to develop an evaluation index system for green mining, which provides the scientific basis for industry experts, researchers, and other stakeholders. The overall framework of the index system based on the DPSIR is shown in Fig. 1.

In the context of mining, the DPSIR model covers important elements related to socio-economic growth (driver), environmental pollution and ecological damage (pressure), the resources and environmental conditions (state), effects on environment and society (impact), and solutions (response) to improve the efficiency, prevent the pressure, recover the state, and reduce the impacts. Accordingly, the model was successfully implemented and integrated with the concepts of green mining and the principles of green mine construction, which provided the basis for the evaluation framework. After theorizing the model, the critical step was to select the primary indicators. It is necessary to consider that too many or a limited number of criteria can lead to a lack of thorough evaluation. Therefore, the choice of indicators was screened out scientifically [17]. In the selection of indicators, aspects of resource and environment were taken into account to analyze cause-effect association more broadly and objectively [31]. The five parameters in the DPSIR model have close causality, which can describe the causal relationships in the system [32]. In this way, a framework of the evaluation index was finally developed to reflect the actual situation of the mines more accurately.

\section{Formulation of the evaluation index}

For the formulation of the evaluation index, both the qualitative and quantitative indicators were included. The evaluation index (shown in Fig. 2) is constituted of three layers, including the target layers, the criterion layer, and the index layer. The target layer outlines the goal, which is the evaluation of green mine construction. The criterion layers consist of five criteria to be evaluated, are described below:

Driver generally refers to human needs, which represent major social, demographic, and economic developments in society, as well as the corresponding changes in lifestyles. In this study, economic growth was listed as a driver.

Pressure indicates the fundamental influencing factors that are directly or indirectly triggered by drivers. Pressures are both specific human activities and natural processes. Unwanted changes, including pollutant emission and high resource consumption, were structured within this criterion.

State is the condition of the environment as a result of pressure. Situations or circumstances, such as the ecological environment and production technology, were included in this criterion.

Impact indicates the results of the interaction of the above three parameters. It is a way in which changes in state influence human well-being. This criterion covers social impact.

Response refers to the institutional measures taken to address changes in state, as prioritized by impacts. Responses have to do with decision making, which seeks to control drivers (prevention or mitigation) to maintain or restore the state and help accommodate impacts

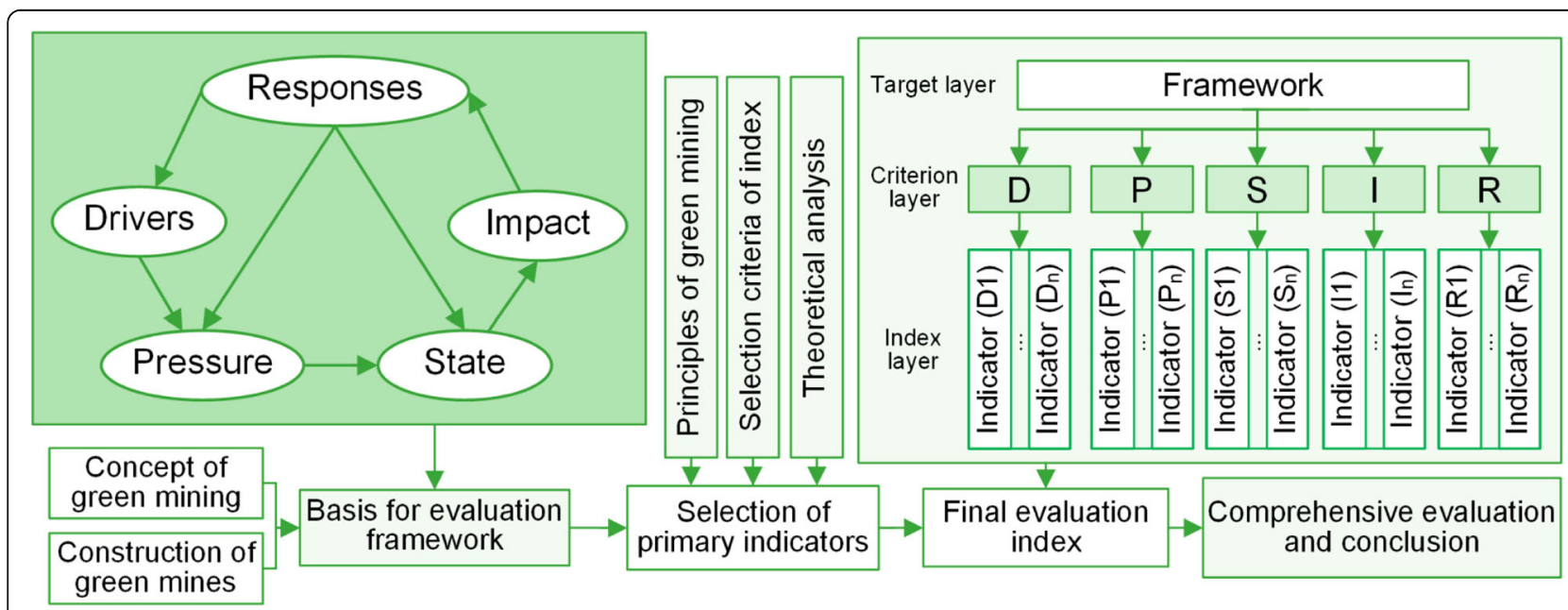

Fig. 1 The framework of the DPSIR model 


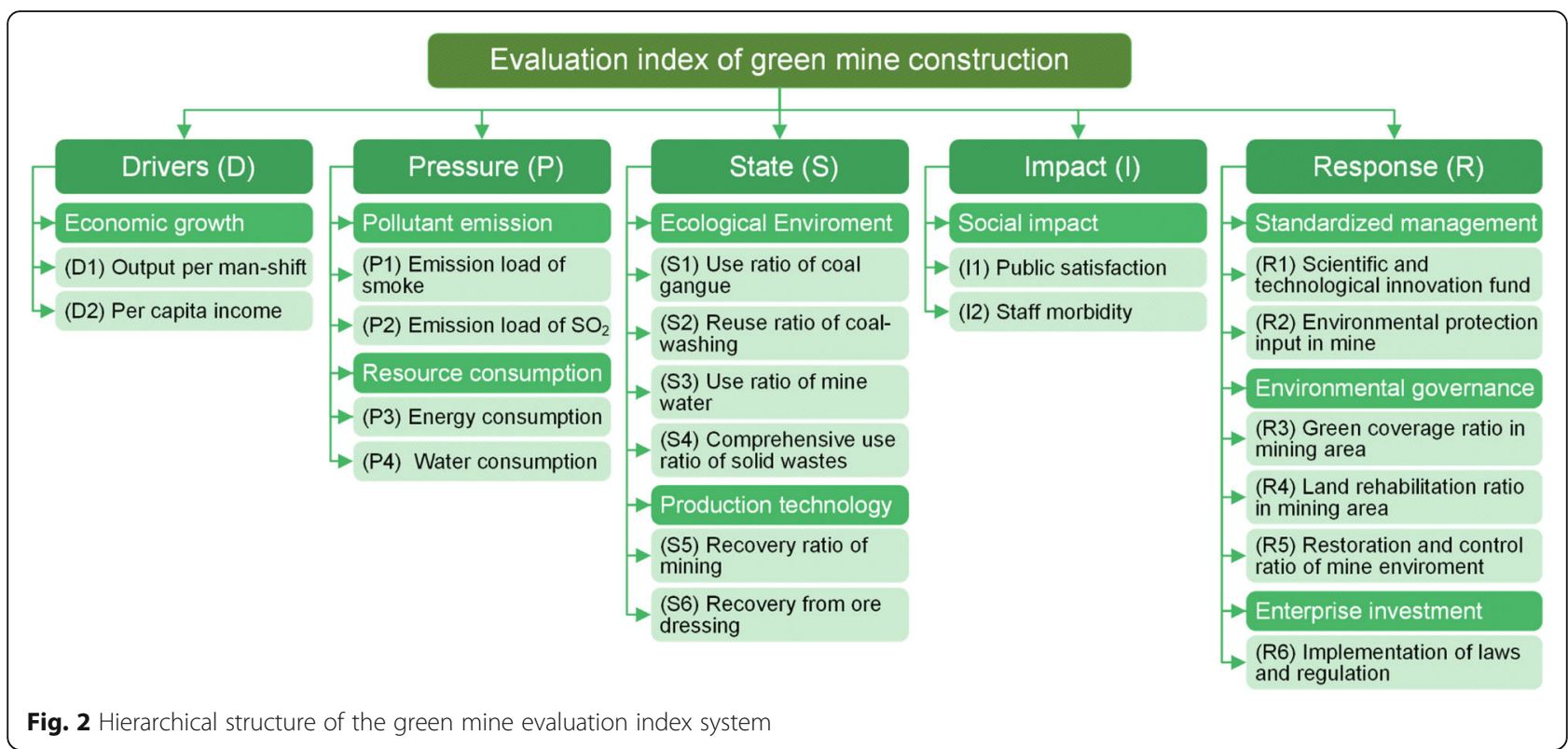

(adaption). Enterprise investment, environmental governance, and standardized management were chosen as the components of this criterion.

The index layer, being the last unit in the framework, includes a total of 20 evaluation indicators (described in Fig. 2) according to the contents of the criterion layer.

\section{Data analysis}

The data used in this study were obtained from the records held in the mines and experts working in the green mines. Despite a wide range of analytic options available, PCA has been applied because it allows high dimensional data to be represented in a more tractable form without losing too much information. Furthermore, under certain circumstances, either some data are missing or recorded in different properties or units. Therefore, it is necessary to standardize the data to make the indicators dimensionless [33], because most of the qualitative and quantitative indicators have specific properties and units. It has been widely recognized that PCA can reduce the information processing workload and avoid repeated information analysis. Therefore, PCA has strong applicability in index selection, evaluation, and prediction [34].

PCA has shown to be an effective method to transform multiple variables into principal components. The process of compressing a large number of input variables into lower dimensions is called dimensionality reduction. The transformed principal components contain most of the information from the original data, which does not overlap with each other. The number of principal components must be determined according to the variance contribution ratio greater than $85 \%$. The next step after dimensionality reduction is to calculate the principal component loading and then carry out the quantitative evaluation. The main steps of PCA, as used in the literature of evaluation index [34, 35], are:

1) In the first step, data were standardized to improve the accuracy of data analysis and eliminate the influence of the data dimension. Eq. (1) was used to standardize the original data.

$$
z_{i j}=\frac{x_{i j}-\bar{x}_{j}}{s_{j}}
$$

In the above equation, $z_{i j}$ is the normalized value of $x_{i j}$ (initial value). This is to say that it is standardized data of the $j^{t h}$ index value of the $i^{t h}$ index layer. The element $\bar{x}_{j}$ is the average value of the selected sample, calculated using Eq. (2), whereas $S_{j}$ is the standard deviation of $j^{\text {th }}$ indicator obtained using Eq. (3).

$$
\begin{aligned}
& \overline{x_{j}}=\frac{1}{m} \sum_{i=1}^{m} x_{i j} \\
& \mathrm{~S}=\sqrt{\frac{1}{m-1} \sum_{i=1}^{m}\left(x_{i j}-\bar{x}_{j}\right)^{2}}
\end{aligned}
$$

2) After the data were standardized, it was evaluated for applicability to examine the correlation among variables of initial data to determine whether selected samples were suitable for PCA. 
Bartlett's sphericity test and Kaiser-Meyer-Olkin (KMO) test are usually used to examine the suitability of data for PCA [36, 37]. Here, the KMO test was adopted, which is mainly used to measure sampling adequacy. The value interval of KMO is $[0,1]$, indicating the correlation among indicators. When the value of $\mathrm{KMO}$ is close to 1 , it shows that the correlation among all variables is very strong, and the selected sample is appropriate for PCA. Whereas, if the KMO value is close 0 , the selected sample is considered unsuitable for PCA. The measurement standards of KMO are shown in Table 1.

3) In the third step, the correlation coefficient matrix $R$ was calculated using Eqs. (4) and (5).

$$
\begin{aligned}
& R=\left(r_{i j}\right)_{p} x p=\frac{Z^{T} Z}{n-1} \\
& r_{i j}=\frac{\sum Z_{k j} \cdot Z_{k j}}{n-1}, i, j=1,2, \cdots, p
\end{aligned}
$$

where, $Z^{T}$ is the transpose of $Z$, which is the standardization matrix.

4) The fourth step was to calculate the eigenvalue $\lambda_{p}$ of the $R$ value and to determine the number of principal components $m$ according to the principle of variance contribution ratio greater than $85 \%$ ( $\sum_{j=1}^{m} \lambda_{j} / \sum_{j=1}^{p} \lambda_{j} \geq 85 \%$ ).

5) The last step was to calculate the principal component loading and determine the comprehensive evaluation score $F$ for each principal component $\left(Y_{p}\right)$ using Eq. (6).

$$
F=\sum_{p=1}^{n} a(p) Y_{p}
$$

\section{Results}

\section{Status of green mining}

The mining area in Yongcheng City (Fig. 3) belongs to the late Paleozoic era of the coal-bearing region in

Table 1 Measurement standards of the KMO value

\begin{tabular}{ll}
\hline KMO Value & Applicability \\
\hline $0.90-1.00$ & Extremely suitable \\
$0.80-0.89$ & Very suitable \\
$0.70-0.79$ & Average \\
$0.60-0.69$ & Suitable \\
$0.50-0.59$ & Unsuitable \\
$0.00-0.49$ & Quite \\
\hline
\end{tabular}

northern China. So far, 25 layers of coal seams have been discovered, including seven layers of minable seams and some partially minable seams. The average thickness of the main minable seams is $1.36-2.84 \mathrm{~m}$ and the burial depth of the coal seams is about $225-1000 \mathrm{~m}$. According to the data from 2012 to 2015, the green mine construction in the Yongcheng mining area has made considerable progress. As shown in Table 2, the ratio of environmental protection, land rehabilitation, and comprehensive utilization of resources has linearly increased. From the perspective of community harmony and enterprise culture, working injuries have been decreased with the increase in the ratio of safety training.

\section{Evaluation of green mine construction}

The results of four-year data compiled through data standardization processing are presented in Table 3. According to the KMO test results in measuring the sampling adequacy for each variable in the model, a value of 0.687 was obtained, which is suitable for analysis. Based on the $\mathrm{R}$ value, the principal components of each indicator extracted during PCA were analyzed, and the results are shown in Table 4. It can be seen that the total variance and the cumulative percentage of variance calculated from the initial data are higher than $90 \%$. The variance percentage of the three components, namely $Y_{1}, Y_{2}$, and $Y_{3}$, was $84.5,11.4$, and $4.1 \%$, respectively. Among the three components, $Y_{3}$, with a value of $4.1 \%$, showed a weak explanatory capability for green mine construction. However, the cumulative variance ratio reached $95.9 \%$ for the first two components. Therefore, according to the principle that the variance contribution ratio should be higher than $85 \%$, thus, $Y_{1}$ and $Y_{2}$ were extracted.

Values in the principal component load matrix represent the correlation coefficients of indicators of the principal components. The loadings can be understood as the weights for each original variable when calculating the principal component. The results presented in Table 5 show that, on average, per capita income of staff $\left(\mathrm{D}_{2}\right)$ has strong positive loadings, and staff morbidity $\left(\mathrm{I}_{2}\right)$ has strong negative loadings. Large (either positive or negative) loadings indicate that a variable has a strong effect on that particular principal component. In addition, index loads of $\mathrm{P}_{2}, \mathrm{P}_{4}, \mathrm{~S}_{3}, \mathrm{R}_{3}, \mathrm{R}_{4}$ and $\mathrm{R}_{5}$ in $\mathrm{Y}_{1}$ were significant with the values of $0.908,0.911,0.971$, $0.975,0.934$ and 0.821 , respectively, indicating that $\mathrm{Y}_{1}$ could comprehensively reflect the pollutant emission, resource consumption, ecological environment, environmental governance, etc. In $Y_{2}$, index loads for $R_{1}, P_{4}$, and $S_{5}$ in $Y_{2}$ were high with the values of $0.912,0.455$, and 0.282 , respectively. It implies that $\mathrm{Y}_{2}$ comprehensively reflects enterprise investment, resource consumption, and production technology. 


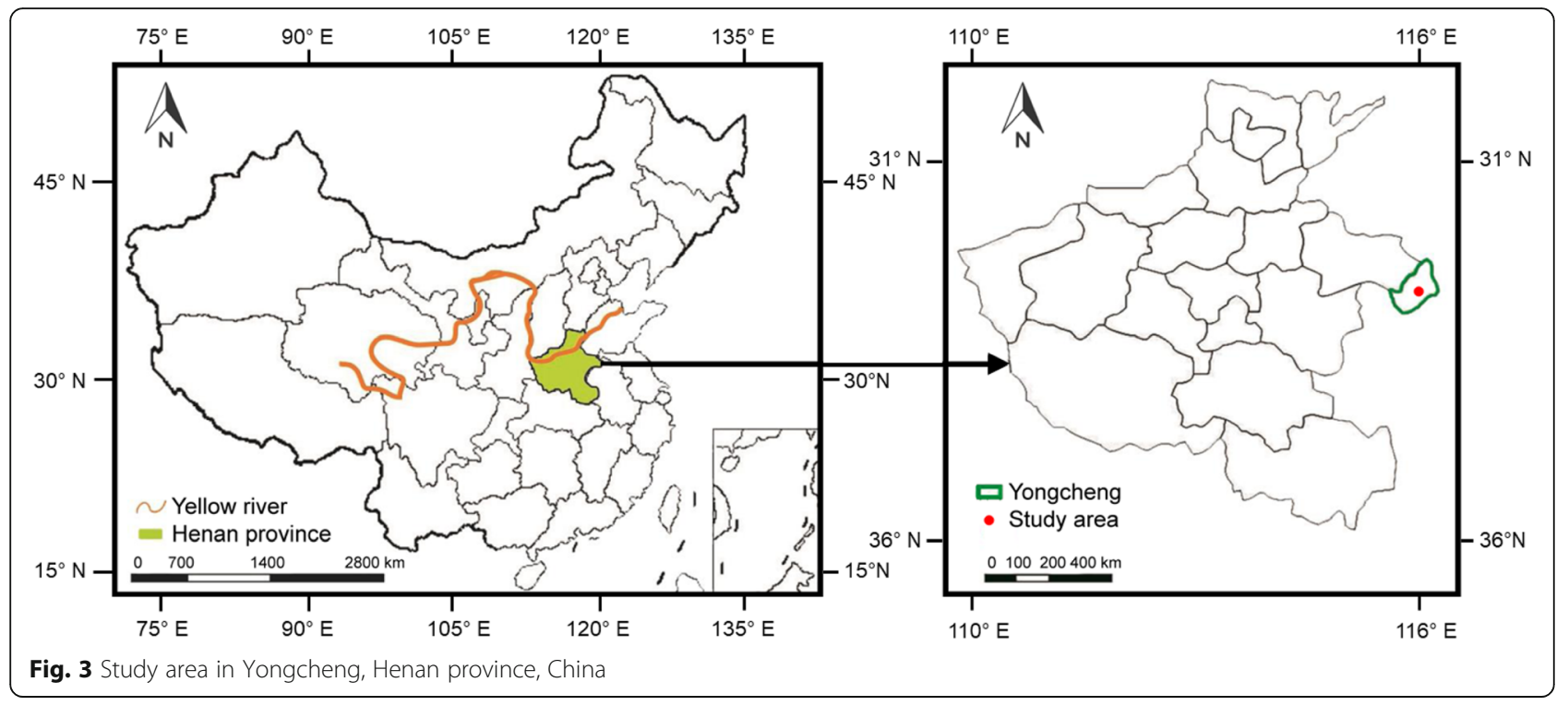

The PCA score of the comprehensive evaluation value of green mine construction was calculated as $F=$ $0.8454 Y_{1}+0.1138 Y_{2}$. The results of the PCA factors presented in Table 6 reflect a progressive increase in the construction of green mines. Multiple indicators show a good development trend of green mining. Among these, ore dressing recovery $\left(\mathrm{S}_{6}\right)$ has been improved over the years, and $\mathrm{SO}_{2}$ emission $\left(\mathrm{P}_{2}\right)$ and energy consumption $\left(\mathrm{P}_{3}\right)$ slightly decreased. Meanwhile, the green coverage ratio in the mining area $\left(R_{3}\right)$ and the restoration of mine environment $\left(R_{5}\right)$ significantly increased. It implies that the construction level of mine has mostly improved in terms of resource utilization, environmental governance, and management capacity. However, it should also be noted that the values of $Y_{2}$ are lower than that of $Y_{1}$. The main influencing factors of $Y_{2}$ were the proportion of scientific and technological innovation fund $\left(\mathrm{R}_{1}\right)$, water consumption $\left(\mathrm{P}_{4}\right)$, and the recovery ratio of mining $\left(\mathrm{S}_{5}\right)$. However, it is necessary to point out that $\mathrm{Y}_{2}$ is higher than 0 after 2014. It implies that the scientific and technological innovation fund, mine production value, water resource consumption, and the recovery ratio of mining also improved. The analytical ability of $\mathrm{Y}_{3}$ to initial index information was weak. Therefore, it was not analyzed.

\section{Discussion}

In this study, a multi-level evaluation index consisting of critical indicators for assessing the level of green mine construction was established based on the DPSIR model. The weight values at all levels in the evaluating system were calculated using PCA. The results show that the status of green mine construction has improved significantly over the years. The main findings indicate that the development mode of the circular economy was further expanded, and energy consumption and pollutant emissions were minimized. It is worth noting that the harmony of economic development and the protection of the ecological environment was realized. Secondary processing and utilization of waste produced during the

Table 2 Percentage (\%) of green mining implementation

\begin{tabular}{|c|c|c|c|c|c|}
\hline Index & & 2012 & 2013 & 2014 & 2015 \\
\hline \multirow[t]{3}{*}{ Environmental protection and land rehabilitation } & Green coverage ratio & 20 & 24 & 34 & 46 \\
\hline & Land rehabilitation ratio & 26 & 31 & 46 & 48 \\
\hline & Restoration and control ratio of mine environment & 31 & 42 & 48 & 79 \\
\hline \multirow[t]{4}{*}{ Comprehensive utilization } & Utilization ratio of solid wastes & 48 & 61 & 71 & 91 \\
\hline & Reuse ratio of mine wastewater & 78 & 82 & 83 & 91 \\
\hline & Recovery ratio of working face & 92 & 93 & 95 & 97 \\
\hline & Rate of comprehensive utilization of mineral resources & 34 & 46 & 51 & 58 \\
\hline \multirow[t]{2}{*}{ Community harmony and enterprise culture } & Injury ratio per million working hours & 2.02 & 1.22 & 0.96 & 0.23 \\
\hline & Number of safety training per person per month* & 1 & 2 & 3 & 4 \\
\hline
\end{tabular}


Table 3 Standardized data of each indicator

\begin{tabular}{|c|c|c|c|c|c|c|}
\hline \multirow{2}{*}{$\frac{\text { Influencing factor }}{\text { Economic growth }}$} & \multicolumn{2}{|c|}{ Indicator } & \multirow{2}{*}{$\frac{2012}{-0.091}$} & \multirow{2}{*}{$\frac{2013}{0.531}$} & \multirow{2}{*}{$\frac{2014}{0.665}$} & \multirow{2}{*}{$\frac{2015}{0.947}$} \\
\hline & D1 & Output per man-shift $\left(\mathrm{t} \mathrm{yr}^{-1}\right.$ person $\left.^{-1}\right)$ & & & & \\
\hline & D2 & Per capita income development of staff & -0.105 & 1.245 & 1.294 & 1.963 \\
\hline \multirow[t]{2}{*}{ Pollutant emission } & P1 & Emission load of smoke & 0.113 & -0.107 & -0.776 & -0.987 \\
\hline & P2 & Emission load of $\mathrm{SO}_{2}$ & 0.612 & 0.077 & -0.812 & -1.431 \\
\hline \multirow[t]{2}{*}{ Resource consumption } & P3 & Energy consumption of unit mine production & 0.698 & -0.066 & -0.923 & -0.994 \\
\hline & P4 & Water consumption of unit mine production & 1.278 & -0.362 & -0.868 & -0.883 \\
\hline \multirow[t]{4}{*}{ Ecological environment } & S1 & Use ratio of coal gangue & -0.160 & -0.158 & 0.913 & 0.913 \\
\hline & $\mathrm{S} 2$ & Reuse ratio of coal-washing wastewater & -0.191 & 0.285 & 0.774 & 0.770 \\
\hline & $\mathrm{S3}$ & Use ratio of mine water & -0.727 & -0.343 & 0.302 & 1.606 \\
\hline & S4 & Comprehensive use ratio of solid wastes & 0.090 & 0.553 & 0.556 & 0.551 \\
\hline \multirow[t]{2}{*}{ Production technology } & S5 & Recovery ratio of mining & 0.172 & -0.351 & 0.937 & 0.782 \\
\hline & S6 & Ore dressing recovery percentage & 0.055 & 0.254 & 0.384 & 0.986 \\
\hline \multirow[t]{2}{*}{ Social impact } & 11 & Public satisfaction & -0.457 & -0.303 & 0.655 & 1.335 \\
\hline & 12 & Staff morbidity & 1.258 & 0.009 & -1.271 & -1.723 \\
\hline \multirow[t]{2}{*}{ Enterprise investment } & R1 & $\begin{array}{l}\text { Proportion of scientific and technological innovation fund in } \\
\text { mine production value }\end{array}$ & 1.130 & -0.582 & 0.235 & 1.608 \\
\hline & $\mathrm{R} 2$ & $\begin{array}{l}\text { Proportion of environmental protection input in mine } \\
\text { production value }\end{array}$ & -0.836 & 0.392 & 0.041 & 0.937 \\
\hline \multirow[t]{3}{*}{ Environmental governance } & R3 & Green coverage ratio in mining area & -0.726 & 0.009 & 0.839 & 1.514 \\
\hline & R4 & Land rehabilitation ratio in mining area & -0.735 & -0.295 & 0.757 & 1.311 \\
\hline & R5 & Restoration and control ratio of mine environment & -0.425 & 0.084 & 0.684 & 1.513 \\
\hline Standardized management & R6 & Implementation of laws and regulations & -0.443 & -0.448 & 1.045 & 1.042 \\
\hline
\end{tabular}

mining process were practiced to maintain the state of the environment. However, some early problems left over by history, such as environmental pollution, gangue accumulation, and land subsidence, etc., were not entirely resolved, which hinders the further development of green mine construction. More improvements are needed to reduce water consumption, land rehabilitation, implementation of laws and regulations, and public satisfaction.

In view of the obtained research results, it can be projected that socio-economic development, technological innovation, and change of social concept put pressure on the environment. These pressures lead to changes in the state of resources, production, and economic benefits, which can promote positive impacts or cause negative impacts depending on the factor. An intelligent response to this can improve positive driving forces, reduce pressures, eliminate the adverse impacts, and maintain the original state of the environment. In view of such compelling circumstances, Fig. 4 highlights some requirements and solutions for promoting green mine construction, which are discussed below.

In general, technological innovation and progress will accelerate the adoption of green mining in the long run. Environmental protection through land reclamation plays a leading role in environmentally sustainable mining operations. Energy conservation and comprehensive utilization of resources are the main pillars of green mining, which require immediate and continuous

Table 4 Total contribution ratio of variance

\begin{tabular}{|c|c|c|c|c|}
\hline \multirow[t]{2}{*}{ Values } & \multirow[t]{2}{*}{ Description } & \multicolumn{3}{|c|}{ Component } \\
\hline & & $\mathrm{Y1}$ & Y2 & Y3 \\
\hline \multirow[t]{3}{*}{ Initial eigenvalue } & Total & 11.2 & 1.5 & 0.5 \\
\hline & Percentage of variance & 84.5 & 11.4 & 4.1 \\
\hline & Cumulative percentage & 84.5 & 95.9 & 100 \\
\hline \multirow[t]{3}{*}{ Loaded values of extracted quadratic sum } & Total & 11.2 & 1.5 & \\
\hline & Percentage of variance & 84.5 & 11.4 & \\
\hline & Cumulative percentage & 84.5 & 95.9 & \\
\hline
\end{tabular}


Table 5 Principal component load matrix of green mine construction

\begin{tabular}{|c|c|c|}
\hline \multirow{2}{*}{$\begin{array}{l}\text { Influencing } \\
\text { factors }\end{array}$} & \multicolumn{2}{|c|}{ Principal components } \\
\hline & $\mathrm{Y1}$ & $\mathrm{Y} 2$ \\
\hline$\overline{\mathrm{D} 1}$ & 0.416 & -0.123 \\
\hline D2 & 0.795 & $0.284^{*}$ \\
\hline P1 & -0.519 & -0.051 \\
\hline P2 & $-0.908^{*}$ & -0.060 \\
\hline P3 & -0.779 & 0.127 \\
\hline P4 & $-0.911 *$ & $0.455^{*}$ \\
\hline S1 & 0.571 & 0.123 \\
\hline S2 & 0.444 & -0.094 \\
\hline S3 & $0.971^{*}$ & 0.218 \\
\hline S4 & 0.179 & -0.147 \\
\hline S5 & 0.426 & $0.282^{*}$ \\
\hline S6 & 0.367 & 0.074 \\
\hline 11 & $0.819 *$ & 0.200 \\
\hline 12 & $-1.332^{*}$ & 0.154 \\
\hline R1 & 0.275 & $0.912^{*}$ \\
\hline R2 & 0.618 & -0.246 \\
\hline R3 & $0.975^{*}$ & 0.001 \\
\hline R4 & $0.934^{*}$ & 0.095 \\
\hline R5 & $0.821^{*}$ & 0.077 \\
\hline R6 & 0.792 & 0.173 \\
\hline
\end{tabular}

*Strong loading weight

attention. A standardized enterprise management system pursuing green innovation strategies is of great significance for establishing a green enterprise culture and communal harmony, which in turn can play a positive role in promoting the development of green mines. Law enforcement, effective policies, and government regulations tend to be the most effective means to control adverse environmental impacts and speed up the transition from existing mines to green mines. The recommendations to provide scientific support for the future framework of green mining development are discussed below.

\section{Scientific planning of green mine construction}

The development of green mining requires a transition of existing strategies towards more scientific approaches

Table 6 Scores of PCA factors of green mine construction

\begin{tabular}{llll}
\hline Year & Y1 & Y2 & $F$ \\
\hline 2012 & -9.022 & -6.428 & -8.359 \\
2013 & -0.521 & -1.377 & -0.597 \\
2014 & 5.234 & 0.315 & 4.46 \\
2015 & 9.178 & 1.393 & 7.917 \\
\hline
\end{tabular}

focusing on future needs. The goal-oriented scientific planning with the major focus on key issues of mineral development and utilization, economic development and environment protection should be carried out in compliance with national policies and practical conditions of the mining area [38]. Scientific planning should also consider the specific directions for ecological reconstruction and environmental governance with effective management mechanisms and measures to ensure the comprehensive utilization of resources.

\section{Promotion of digitalization and informatization in mining areas}

The key to green mine construction is technology driven. In order to reduce energy and resource consumption, digitalization and informatization techniques must be adopted to improve the level of equipment automation. In the future, technology development will be intensified, and the upgrade cycle will be continuously shortened, so the potential of technological innovation and comprehensive research needs to be improved. In addition, advances in intelligent mining have to be vigorously made on the basis of artificial intelligence to fully transform the current mining pattern into a more reliable and smarter mining system [5].

\section{Implementation of responsibility system and management}

Each mining area should form a unique management mechanism system based on the experience of advanced enterprises in China and abroad. At the same time, a comprehensive management network system must be established with a clear division of unequivocal accountability as an approach to improve the standardization level of enterprise management.

\section{Transition from a linear economy to the circular economy mode}

The circular economy is an alternative to the traditional linear economy developed in the area of environmental economics. In a linear economy, raw materials are first mined, then processed into products, and discarded after use. However, in the circular economy mode, resources are used as long as possible to get the maximum value and finally recycled to reuse the waste. Hence, the traditional economy "resource - production - pollution emission" should be transformed into the circular economy "resource - production - renewable resources", in which resources can be extracted to the maximum extent, used for a long time, and regenerated for reuse [39]. In order to build and accelerate the transition to the circular economy, the fundamental principle of green mining that focuses on balancing economic growth, resource sustainability, and environmental protection must 


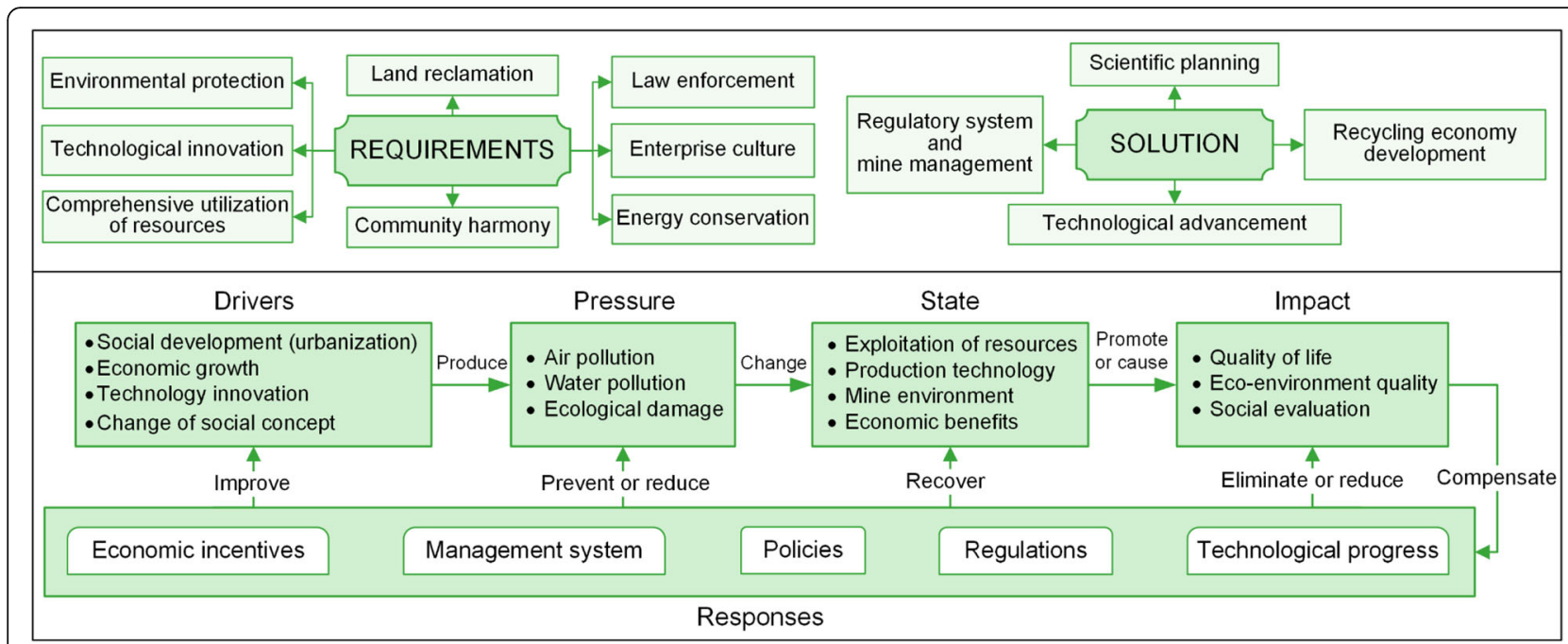

Fig. 4 A comprehensive future framework for the construction of green mines

be applied to achieve optimal production, optimal consumption, and minimum waste.

\section{Conclusions}

The idea of green mining was developed as a key approach to pursue sustainable development. Consequently, the construction of greens has received considerable attention in China to balance resource development and ecological protection. This study attempts to develop an evaluation index system based on the DPSIR model to assess the current status of green mine construction in China. First, several influencing criteria and indicators were chosen under the core principles of green mining. Then, the PCA was used to evaluate them. Finally, a future framework for the development of green mines was proposed.

The results show that the status of green mine construction has significantly improved over the years. The level of mine safety, the ratios of environmental protection, land rehabilitation, and comprehensive utilization of resources have increased. However, some concerns have yet to be addressed, such as the utilization of solid waste, the percentage of recovery from ore processing, and the reuse ratio of the water used for coal washing. Arguably, the practice of green mining can be a longterm sustainable solution, and its implementation can ultimately lead to gain a competitive edge. However, some various hurdles and barriers hinder the implementation of green mining, which needs to be appropriately analyzed. For this purpose, the corresponding countermeasures and suggestions have been proposed to promote the development of green mines.

Particular attention and the highest priority should be given to energy and resource management. A clear and consistent policy, as well as an updated regulatory framework, must be in place to amplify the potential of green innovations. In addition, there has to be a continuous focus on strengthening standardized management, improving enterprise culture, and promoting community harmony. In order to achieve this goal, interdisciplinary collaboration can offer a broad prospect for green mining. The quick and successful implementation of green mining technology can be accomplished through holistic strategies based on scientific planning, promoting digitization and informalization, implementing a responsibility management system, and expanding the circular economy to the individual enterprise level.

The findings of this study have to be seen in the light of some limitations that could be addressed in future research. First, the network of evaluation index is built according to the conditions and situation of the Yongcheng mining area, which can be different from other regions. Second, only two-level indicators have been used, which limits the reliability of the results to a certain extent. Therefore, indicators used in the index should be optimized in future research. Finally, subsidy policies related to green mining need to be carefully investigated on the basis of profits brought by improving the technological level of mining enterprises.

\section{Acknowledgments}

The authors want to thank mining enterprises for their cooperation during fieldwork.

\section{Authors' contributions}

$J \mathrm{C}$ and IMJ have equally contributed to the study design and manuscript drafting. $\mathrm{CJ}$ and $\mathrm{HY}$ helped in data collection and analysis. 


\section{Availability of data and materials}

All data generated or analyzed during this study can be obtained from the corresponding author.

\section{Competing interests}

The authors declare they have no competing interests.

\section{Author details}

'Dongying Natural Resources Bureau, Dongying 257091, China. ${ }^{2}$ Keda Group Co., Ltd., Dongying 257091, China. ${ }^{3}$ China University of Petroleum, Qingdao 266580, China. ${ }^{4}$ School of Mines, China University of Mining and Technology, Xuzhou 221116, China. ${ }^{5}$ Management Center of Sustainable Development Research Institute of Yellow River Delta, Dongying 257091, China.

Received: 11 March 2020 Accepted: 4 June 2020

Published online: 16 June 2020

\section{References}

1. Lei YL, Cui N, Pan DY. Economic and social effects analysis of mineral development in China and policy implications. Resour Policy. 2013;38:44857.

2. Jiskani IM, Cai QX, Zhou W, Chang ZG, Chalgri SR, Manda E, et al. Distinctive model of mine safety for sustainable mining in Pakistan. Mining Metall Explor. 2020; https://doi.org/10.1007/s42461-020-00207-8.

3. Hao ZG, Fei HC, Liu L, Hao QQ, Turner S. World's third-largest molybdenum deposit discovered in Caosiyao area, Xinghe County, Inner Mongolia. Acta Geol Sin-Engl. 2014;88:1615-6.

4. Liu JN, Su YL, Lin H. Research on China's mineral resources management system and mechanisms. In: Ren P, Du Z, editors. WIT transactions on information and communication technologies. Vol. 46. Southampton: WIT Press; 2013. p. 2695-702.

5. Wang GF, Xu YX, Ren HW. Intelligent and ecological coal mining as well as clean utilization technology in China: review and prospects. Int J Min Sci Techno. 2019;29:161-9.

6. Sivakumar R, Kannan D, Murugesan P. Green vendor evaluation and selection using AHP and Taguchi loss functions in production outsourcing in mining industry. Resour Policy. 2015;46:64-75.

7. Guo WB, Guo MJ, Tan Y, Bai EH, Zhao GB. Sustainable development of resources and the environment: mining-induced eco-geological environmental damage and mitigation measures-a case study in the Henan coal mining area, China. Sustain Basel. 2019;11:4366.

8. Yu CJ, Li HQ, Jia XP, Li Q. Improving resource utilization efficiency in China's mineral resource-based cities: a case study of Chengde, Hebei province. Resour Conserv Recy. 2015;94:1-10.

9. Li CF, Wang AJ, Chen XJ, Chen QS, Zhang YF, Li Y. Regional distribution and sustainable development strategy of mineral resources in China. Chinese Geogr Sci. 2013;23:470-81.

10. Azapagic A. Developing a framework for sustainable development indicators for the mining and minerals industry. J Clean Prod. 2004;12:639-62.

11. Awan U, Kraslawski A, Huiskonen J. Governing interfirm relationships for social sustainability: the relationship between governance mechanisms, sustainable collaboration, and cultural intelligence. Sustain Basel. 2018;10: 4473.

12. Awan U. Impact of social supply chain practices on social sustainability performance in manufacturing firms. Int J Innov Sustain. 2019;13:198-219.

13. Chattopadhyay S, Chattopadhyay D. Coal and other mining operations: role of sustainability. In: Malhotra R, editor. Fossil energy. 2nd ed. New York: Springer; 2020. p. 333-56.

14. Xu F, Dong YX. China's global strategy of mineral resources under the background of the financial crisis. Appl Mech Mater. 2013;295-8:2696-700.

15. Shen LX, Muduli K, Barve A. Developing a sustainable development framework in the context of mining industries: AHP approach. Resour Policy. 2015;46:15-26.

16. Qian M, Xu J, Miao X. Green technique in coal mining. J China Univ Min Technol. 2003;32:343-8 [in Chinese].

17. Shang DL, Yin GZ, Li XS, Li YJ, Jiang CB, Kang XT, et al. Analysis for Green Mine (phosphate) performance of China: an evaluation index system. Resour Policy. 2015;46:71-84.

18. Nurmi PA. Green mining - a holistic concept for sustainable and acceptable mineral production. Ann Geophys-Italy. 2017;60:1-7.
19. MLR. Guide of Carrying out the National Program of Mineral Resources: Developing the Green Mining and Constructing the Green Mine. Beijing: Ministry of Land and Resources; 2010 [in Chinese].

20. Li CM, Nie R. An evaluating system for scientific mining of China's coal resources. Resour Policy. 2017;53:317-27.

21. Zhou YL, Zhou W, Lu X, Jiskani IM, Cai QX, Liu P, et al. Evaluation index system of green surface mining in China. Min Metall Explor. 2020; https:// doi.org/10.1007/s42461-020-00236-3.

22. Li CM, Nie R, Wang D. Scientific mining in China - problems, progress, and prospects. Electron J Geotech Eng. 2015;20:6491-506.

23. Ma CA, Wang QR. Ecological evaluation model for large opencast mine and its application. J Min Saf Eng. 2006;23:446-51 [in Chinese].

24. Song ZL, Fan JF, Qi WH, Yang XC, Wang JG, Ji YS. Study on the surface coal mine green mining technology and appraising index system. J China Coal Soc. 2016;41:350-8 [in Chinese].

25. Li X, Yang JJ, Yan HC, Cao HJ. Study on evaluation index system of green mine construction. In: 3rd International Conference on Energy, Environment and Materials Science. Singapore; 2017 Jul 28-30.

26. Qian MG, Xu JL. Concept and technical framework of sustainable mining. J China Univ Min Technol. 2011;1-7 [in Chinese].

27. Huang J, Tian CY, Xing LF, Bian ZF, Miao XX. Green and sustainable mining: underground coal mine fully mechanized solid dense stowing-mining method. Sustain Basel. 2017;9:1418.

28. Liu JP, Zhang YD, Yang HJ. Value of green mining in minral resources. J China Univ Min Technol. 2004;33:233-6 [in Chinese].

29. Long RY, Li M. Reasons of positively-lacking and revelation of policy-making on green mining. Ecol Econ. 2007;194-7 [in Chinese].

30. Wang WQ, Sun YH, Wu J. Environmental warning system based on the DPSIR model: a practical and concise method for environmental assessment. Sustain Basel. 2018;10:1728.

31. Henriques C, Garnett K, Weatherhead EK, Lickorish FA, Forrow D, Delgado J. The future water environment - using scenarios to explore the significant water management challenges in England and Wales to 2050. Sci Total Environ. 2015;512:381-96.

32. Kelble CR, Loomis DK, Lovelace $S$, Nuttle WK, Ortner PB, Fletcher P, et al. The EBM-DPSER conceptual model: integrating ecosystem services into the DPSIR framework. PloS One. 2013;8:e70766.

33. Sepehril M, Malekinezhad H, Hosseini SZ, Ildoromi AR. Assessment of flood hazard mapping in urban areas using entropy weighting method: a case study in Hamadan city, Iran. Acta Geophys. 2019;67:1435-49.

34. Shi KY, Liu Y, Zhang ZJ, Yu Q, Zhang QC. Constructing a method for an evaluation index system based on graph distance classification and principal component analysis. Adv Mater Sci Eng. 2019;2019:6015754.

35. Huang $B, X u R$, Fu C, Wang $Y$, Wang $L$. Thief zone assessment in sandstone reservoirs based on multi-layer weighted principal component analysis. Energies. 2018;11:1274

36. Chen YJ, Duan L, Xiao Y. Constructing driving behavior indicators using principal component analysis and combination of fuzzy and grey Delphi method. J Saf Environ. 2012;12:228-32 [in Chinese].

37. Sreejesh S, Mohapatra S, Anusree MR. Business research methods: an applied orientation. Cham: Springer; 2014.

38. Jiang CZ, Bian ZY, Yuan JX. Cluster analysis of mineral resources based on AHP. In: Fourth International Conference on Transportation Engineering. Chengdu; 2013 19-20.

39. Cai HC, Pan M, Wang YZ. Analysis of mineral resources in Liaoning province of China. Adv Mater Res. 2013;803:351-4.

\section{Publisher's Note}

Springer Nature remains neutral with regard to jurisdictional claims in published maps and institutional affiliations. 